\title{
Response of upper and lower airway inflammation to bronchial challenge with house dust mite in Chinese asthmatics: a pilot study
}

\author{
Zheng Zhu ${ }^{1 \#}$, Hongyu Wang ${ }^{2,3 \#}$, Yanqing Xie ${ }^{2}$, Jiaying An ${ }^{2}$, Qiurong $\mathrm{Hu}^{1}$, Shu Xia ${ }^{2}$, Jing $\mathrm{Li}^{1}$, Paul O'Byrne ${ }^{3}$, \\ Jinping Zheng ${ }^{2}$, Nanshan Zhong ${ }^{2}$
}

${ }^{1}$ Department of Allergy and Clinical Immunology, State Key Lab of Respiratory Disease, Guangzhou Institute of Respiratory Health, the First Affiliated Hospital of Guangzhou Medical University, Guangzhou, China; ${ }^{2}$ State Key Lab of Respiratory Disease, National Clinical Research Center for Respiratory Disease, Guangzhou Institute of Respiratory Health, the First Affiliated Hospital of Guangzhou Medical University, Guangzhou, China; ${ }^{3}$ Department of Medicine, Firestone Institute for Respiratory Health, the Research Institute of St. Joe's Hamilton, St. Joseph's Healthcare, McMaster University, Hamilton, ON, Canada

Contributions: (I) Conception and design: Z Zhu, H Wang, J Li, P O’Byrne, J Zheng, N Zhong; (II) Administrative support: H Wang, J Li, P O’Byrne, J Zheng, N Zhong; (III) Provision of study materials or patients: Z Zhu, Y Xie, J An, Q Hu, S Xia, J Li, J Zheng, N Zhong; (IV) Collection and assembly of data: Z Zhu, Y Xie, J An, Q Hu, S Xia; (V) Data analysis and interpretation: Z Zhu, H Wang, Y Xie, J An, Q Hu, S Xia; (VI) Manuscript writing: All authors; (VII) Final approval of manuscript: All authors.

"These authors contributed equally to this work.

Correspondence to: Jinping Zheng, MD, FCCP; Nanshan Zhong, MD, FCCP. State Key Laboratory of Respiratory Disease, National Clinical Research Center for Respiratory Disease, First Affiliated Hospital of Guangzhou Medical University, 151 Yanjiang Road, Guangzhou 510120 , China. Email: jpzhenggy@163.com; nanshan@vip.163.com.

Background: Allergen nasal challenge can induce increase of eosinophils in sputum, but report about eosinophilic inflammation in upper airway after allergen bronchial challenge in Chinese asthmatics was rare. The article aims to evaluate response of upper and lower airways to house dust mite (HDM) allergen bronchial challenge.

Methods: HDM allergen bronchial challenge was carried out in asthmatic patients with allergic rhinitis (AR). Bronchial methacholine challenge and blood test were performed before and at 24 hours after allergen challenge. Nasal lavage and induced sputum for differential cells count and fractional exhaled nitric oxide (FeNO) measurement were performed before, 7 and 24 hours after allergen challenge.

Results: Eighteen asthmatic patients with AR underwent HDM allergen bronchial challenge with no serious adverse events reported. Fifteen patients showed dual asthmatic response (DAR), while 2 patients showed early (EAR) and 1 late asthmatic response (LAR) only. At 24 hours after allergen bronchial challenge testing, average $\mathrm{PC}_{20} \mathrm{FEV}_{1}$ to methacholine significantly decreased (1.58 to $0.81 \mathrm{mg} / \mathrm{mL}, \mathrm{P}=0.03$ ), while both FeNO and the percentage of eosinophils in blood and sputum were significantly increased [52.0 (54.0) to 69.0 (56.0) ppb, $\mathrm{P}=0.01 ; 4.82 \%$ to $6.91 \%, \mathrm{P}<0.001 ; 20.70 \%$ to $27.86 \%, \mathrm{P}=0.03$, respectively], but with no significant differences found in the percentage of eosinophils in nasal lavage (39.36\% to $38.58 \%, \mathrm{P}=0.89)$. However, at 7 hours after allergen challenge, the eosinophils in sputum were significant increased to $40.45 \%(\mathrm{P}<0.001)$, but there was an increase (39.36\% to 48.07\%) with no statistical difference ( $\mathrm{P}=0.167)$ found in nasal lavage.

Conclusions: HDM allergen bronchial challenge induced different response of airway inflammation in upper and lower airways.

Keywords: Allergic rhinitis (AR); asthma; allergen; challenge; eosinophils

Submitted Sep 12, 2020. Accepted for publication Jul 15, 2021.

doi: $10.21037 /$ jtd-20-2876

View this article at: https://dx.doi.org/10.21037/jtd-20-2876 


\section{Introduction}

The prevalence of asthma is increasing over the past few decades in China (1,2). Allergic rhinitis (AR) and asthma often coexist. The comorbidity may exist in childhood that persist in adulthood, which have great impact on asthma $(3,4)$. Airway hyperresponsiveness (AHR) and airway eosinophilic inflammation are two main features of AR and asthma, and AHR is also associated with airway inflammation (5). Allergen bronchial challenge can induce an early asthmatic response (EAR), late asthmatic response (LAR) or dual asthmatic response (DAR) with typical lower airway symptoms (6-8) and can induce a significantly increase of eosinophilic inflammation in lower airway $(5,9)$. It is generally assumed that the EAR can be attributed by the release of a range of biologically active compounds, including histamine, prostaglandins $\left(\mathrm{PGD}_{2}\right.$ and $\left.\mathrm{PGF}_{2 \mathrm{a}}\right)$ and leukotrienes, which were following IgE-mediated mast cell degranulation, and basophils may also play a vital role in EAR and eosinophilic inflammation in allergic asthma. However, LAR and the increase of AHR after allergen challenge were associated with allergen-induced airway eosinophilic inflammation that promoted by type 2 cytokines (10-13). AR and asthma are common chronic airway disease with both systematic and local airway inflammation reaction to allergen exposure. Allergen inhalation challenge can induce increased eosinophil progenitors in bone marrow and increased eosinophil in circulation 24 hours after allergen inhalation (14). The onset of an important and persistent Th2-driven inflammatory process dominated by eosinophils presence at one site of the airways, may release into the bloodstream several cytokines that can lead to the stimulation of the bone marrow, which may function as a systemic amplifier of such an eosinophilic inflammation in both sites of airway (4). Our previous study has reported that house dust mite (HDM) allergen nasal challenge could induce an increase of eosinophils in lower airways and circulation (5).

The result of a national survey showed that HDM was the most prevalent allergen and main risk factor for AR and asthma patients in China (14). Although the HDM allergen specific immunotherapy for $\mathrm{AR}$ and asthma has been applied clinically for more than 20 years in China, airway response to HDM allergen bronchial challenge has not been evaluated in Chinese asthmatic patients. The aim of this study was to investigate the airway response to HDM allergen (Dermatophagoides pteronyssinus, Der p) bronchial challenge and to evaluate the changes and correlations of upper and lower airway inflammation before and after HDM allergen (Der p) bronchial challenge in Chinese AR with asthma patients.

We present the following article in accordance with the STROBE Checklist (available at https://dx.doi. org/10.21037/jtd-20-2876).

\section{Methods}

\section{Subjects}

Asthmatic patients with AR from the outpatient clinic of respiratory and allergy department in the First Affiliated Hospital of Guangzhou Medical University were screened. Subjects met the following criteria were recruited: intermittent mild AR with stable mild asthma patients who fulfilled the GINA (15) and ARIA (16) international guidelines, aged 18 to 55 years old, HDM (Der p) was considered as their major allergen by skin prick test and Der p-specific IgE measurement. The exclusion criteria are as follows: subjects who were receiving specific allergen immunotherapy, pregnant or breastfeeding women, smokers, had acute upper or lower airway infection in the past 4 weeks, with history of any other chronic respiratory diseases (e.g., bronchiectasis, chronic obstructive pulmonary disease). Antihistamines, leukotrienes receptor antagonists and corticosteroids were withheld for at least 2 weeks. Inhaled short-acting Beta2 agonist (SABA) was used as needed during the study.

\section{Study design}

This study was designed as a single center, non-randomized open-label trial. After screening, eligible asthmatic patents with AR attended our center on three consecutive days (the flow chart shows in Figure 1). Briefly, on visit 1, fractional exhaled nitric oxide (FeNO), nasal lavage, bronchial challenge to methacholine (Mch), induced sputum, and skin endpoint titration testing (using Der $\mathrm{p}$ allergen) were conducted. On visit 2, HDM allergen bronchial challenge testing was performed to each participant. During the allergen bronchial challenge, $\mathrm{FEV}_{1}$ was measured at baseline, 10, 20, 30, 45, 60, 90, $120 \mathrm{~min}$ in the first 2 hours, and hourly during 3-7 hours after the last or inhalation that cause at least $20 \%$ fall of $\mathrm{FEV}_{1}$. FeNO, nasal lavage and induced sputum were performed at 7 hours after allergen challenge. On visit 3 (24 hours after the HDM inhalation challenge), FeNO, nasal lavage, bronchial challenge to 


\begin{tabular}{cccc} 
Screening & \multicolumn{3}{c}{ Allergen bronchial challenge (ABC) } \\
\hline Disease history & V1 24 h pre-ABC & V2 ABC & V3 24 h post-ABC \\
Allergen SPT & FeNO & 7 h post-ABC & FeNO \\
Spirometry & Nasal lavage & FeNO & Nasal lavage \\
& Peripheral blood & Nasal lavage & Peripheral blood \\
& Sputum induction & Sputum induction & Sputum induction \\
& Mch-BPT & & Mch-BPT
\end{tabular}

Figure 1 study flowchart.

methacholine, and induced sputum were performed. Differential inflammation cells count was performed in nasal lavage, induced sputum, and peripheral blood (PB).

The study was conducted in accordance with the Declaration of Helsinki (as revised in 2013). The study protocol was approved by the Ethics Committee of the First Affiliated Hospital of Guangzhou Medical University (NCT02504528), and written informed consent was obtained and signed by each subject prior to the study.

\section{Allergen skin prick tests and titration}

According to previously published methods (17), sensitive allergens were tested by skin prick test to a panel of common aeroallergens, including Dermatophagoides pteronyssinus (Der p), Dermatophagoides farina (Der f), Blomia tropicalis, cockroach, dogs, cats, Alternaria alternata, Blattella germanica, mixed tree pollen, mixed grass, and a positive (histamine) and negative (diluent) control (ALKAbello, Hørsholm, Denmark). After the skin prick test has been conducted, as the HDM was the major allergen, serial 2-fold dilutions of HDM (Der p, 100,000 SQ-U/mL, ALK-Abelló A/S, Hørsholm, Denmark) were prepared and used by pricking the skin to identify the lowest titration of allergen which causes a skin wheal at least $2 \mathrm{~mm} \times 2 \mathrm{~mm}$ in size. The serial of 2 -fold dilutions were made starting from $1: 4$ through 1:1,024, and beyond 1:1,024 if necessary, which were the same as those allergen dilutions used for allergen bronchial challenge tests.

\section{Methacholine and HDM allergen bronchial challenge tests}

Methacholine bronchial challenge tests were conducted according to the method described by Cockcroft DW with forced expiratory volume in $1 \mathrm{~s}\left(\mathrm{FEV}_{1}\right)$ measured by using spirometers (Jaeger, Germany) on the first visit and third visit (18). The HDM allergen (Der p) bronchial challenge tests were performed on the second visit according to the method reported by Diamant et al. (6). Methacholine solution (Provocholine, Methapharm Inc. Brantford, ON, Canada) or allergen dilution (Derp Aquagen, 100,000 SQ-U/mL, ALK-Abelló A/S, Hørsholm, Denmark) was administered in a series of double increasing concentration by 2 min tidal breathing method with using English-Wright nebulizer (Roxon Medi-Tech, Montreal, QC, Canada). During the allergen challenge test, a mouthpiece and noseclip were used to target allergen to the lower airway and to exclude the upper airway direct exposure. The starting allergen concentration would be 3-4 doubling concentrations below that predicted to cause a $20 \%$ fall in the $\mathrm{FEV}_{1}$ (allergen $\mathrm{PC}_{20}$ ) for the early response, which calculated using the $\mathrm{PC}_{20} \mathrm{Mch}$ and the skin test end point (SS) by the prediction formula: ${ }^{10} \log \left(\mathrm{PC}_{20}\right.$ allergen) $=0.68 \times{ }^{10} \log \left(\mathrm{PC}_{20}\right.$ methacholine $\left.\times \mathrm{SS}\right)(6)$. The top concentration of allergen administered was 1:4 dilution. $\mathrm{FEV}_{1}$ was performed at baseline, 10, 20, 30, 45, 60, 90, $120 \mathrm{~min}$ in the first 2 hours, and hourly during 3-7 hours after the last or inhalation that cause at least $20 \%$ fall of $\mathrm{FEV}_{1}(6)$. Inhaled short-acting $\beta_{2}$ receptor agonists were withheld for at least 8 hours before any bronchial challenge test.

\section{Nasal lavage}

Nasal lavage was performed by an experienced technician as previously described (19). The subject sat upright with head poised forward, sterile saline solution $(10 \mathrm{~mL}$, room temperature) was infused into both nostrils for seven times by using a syringe with a sponge adapter. The collected lavage fluid (more than $7 \mathrm{~mL}$ ) was centrifuged for $10 \mathrm{~min}$ at $2,000 \mathrm{rpm}$ at $4{ }^{\circ} \mathrm{C}$, the supernatant fluid removed into a frozen pipe and stored at $-80{ }^{\circ} \mathrm{C}$ for further analysis. The cell pellets were resuspended in $0.2 \mathrm{~mL}$ saline. The cytospin slides were air-dried, fixed in neutral formalin, and stained 
with hematoxylin and eosin. Differential inflammatory cells (200 non-squamous cells) counts were performed by an experienced technician.

\section{Sputum induction and differential cells count}

Differential cells count in the induced sputum were examined with the routine methods in the cough Lab of our institute as previously described (20). After rinsing the mouth, hypertonic saline (3\%) aerosol generated by ultrasound nebulizer (Yuyue, China) was inhaled for 30 minutes in total (with cough every 10 minutes and stopped if got enough sputum during the inhalation). The sputum plug was collected and treated with $0.1 \%$ dithioerythritol (a volume equal to four times the selected sputum), vortexed and incubated at $0{ }^{\circ} \mathrm{C}$ in an ice-water bath. The suspension was filtered through a $48-\mu \mathrm{m}$ nylon filter and then centrifuged for $10 \mathrm{~min}$ at 3,000 rpm under $4{ }^{\circ} \mathrm{C}$. The supernatant fluid was removed into frozen pipes and stored at $-80^{\circ} \mathrm{C}$ for further analysis. A hemacytometer was used for total cell counts and trypan blue staining was applied in determining cell activity. The sedimentation was smeared on glass and fixed in neutral formalin and stained with hematoxylin and eosin. Four hundred non-squamous cells were counted by an experienced lab technician and the count rate of each cell type was expressed as a percentage of the total number of counted cells (eosinophils, neutrophils, macrophages, and lymphocytes) (21).

\section{$\mathrm{FeNO}$}

FeNO was measured by using a portable hand-held NOanalyzer, NIOX MINO Asthma Inflammation Monitor, (Aerocrine AB, Solna, Sweden) according to the ATS/ ERS recommendation (22). Exercise, food, and drinks were prohibited for 2 hours prior to the measurement to obtain a valid result. The patients sat straightly with the mouthpiece at proper height. A nose clip was used to avoid nasal inspiration. After expiration, the patients inserted the mouthpiece and inhaled over 2 to 3 seconds through the mouth from functional residual capacity to total lung capacity, and then exhaled immediately with a constant expiratory flow rate around $0.05 \mathrm{~L} /$ second for 10 seconds. After waiting for 90 seconds, we can read the value of FeNO on the screen.

\section{Statistical analysis}

Statistical analysis was performed by using SPSS 16.0
(SPSS, Inc., Chicago, IL, USA). Normal distribution data were expressed as mean \pm standard deviation $(M \pm S D)$, while abnormal distribution data expressed as median (interquartile range, IQR). Quantile-quantile Plot and Shapiro-Wilk test were used for normal distribution testing. Paired $t$-tests were performed for the comparison of $\mathrm{PC}_{20}$ before and after allergen challenge. Multiple tests (Oneway ANOVA or Friedman test) were used to compare the differences of the parameters measured before, at $7 \mathrm{~h}$ and $24 \mathrm{~h}$ after allergen challenge. $\mathrm{P}$ value $<0.05$ was considered as statistically significant difference. The correlations between eosinophils in upper and lower airways and PB were analyzed by Pearson correlation test and displayed by Heatmap graphic created with GraphPad Prism 7.

\section{Results}

\section{Study population demographics and baseline information}

Twenty-four AR with asthma patients were screened, and eighteen patients $(\mathrm{M} / \mathrm{F}, 7 / 11,33.6 \pm 9.6$ years of age and $162.2 \pm 8.5 \mathrm{~cm}$ in height) completed this study (6 had not finished all measurements). HDM was the major allergen of these patients and the sensitive profiles were as follows: 18 sensitive to both Der $\mathrm{p}$ and Der f allergen, 10 to Blomia tropicalis, 11 to cockroach, 8 to dog and 3 to cat dander. There was a relatively large variation range of the sensitization degree of the subjects with mean Der p specific $\operatorname{IgE}$ and total $\mathrm{IgE}$ in serum were $43.2 \pm 25.9$ and $287.6 \pm 192.2 \mathrm{kU} / \mathrm{L}$. Of these stable mild asthma patients, inhaled SABA $(4 / 18)$ or inhaled corticosteroid (ICS, 3/18) or inhaled corticosteroid and long-acting Beta2 agonist (ICS/LABA, 10/18) were used as needed or maintenance treatment two weeks before this study. Demographics and baseline information are presented in Table 1.

\section{Results of allergen bronchial challenge and changes of AHR to methacholine}

Among all subjects, 2/18 had EAR only, 1/18 had LAR only, and 15/18 had DAR (show in Table 2). The mean percent decrease of $\mathrm{FEV}_{1}$ was $23.22 \% \pm 3.76 \%$ in early phase response, $29.03 \% \pm 9.84 \%$ in late phase response among patients with DAR (Figure 2). The decreased $\mathrm{FEV}_{1}$ during EAR recovered in 30 minutes after rest, while in $\mathrm{LAR} \mathrm{FEV}_{1}$ recovered to baseline levels with bronchodilator inhaler (Salbutamol, $200 \mathrm{mcg}$ ) 7 hours post allergen challenge. The main respiratory symptoms induced by allergen challenge 
Table 1 Demographic information and baselines

\begin{tabular}{|c|c|c|c|c|c|c|c|c|c|c|c|}
\hline NO. & Gender & $\mathrm{BMI}, \mathrm{kg} / \mathrm{m}^{2}$ & Age, yrs & Allergen (SPT) & $\begin{array}{c}\text { Dp s-lgE, } \\
\text { KU/L }\end{array}$ & T-IgE, KU/L & Medication* & FeNO, ppb & $\begin{array}{c}\text { Eos in Sp, } \\
\quad \%\end{array}$ & $\begin{array}{l}\mathrm{FEV}_{1} \text {, } \\
\text { \%pred }\end{array}$ & $\mathrm{PC}_{20} \mathrm{Mch}, \mathrm{mg} / \mathrm{mL}$ \\
\hline 1 & $\mathrm{~F}$ & 22.2 & 24 & Dp Df cockroach & 11.2 & 102 & SABA & 52 & 29.0 & 75 & 0.33 \\
\hline 3 & $\mathrm{~F}$ & 21.6 & 30 & Dp Df dog cat & 52.2 & 445 & ICS/LABA & 102 & 35.5 & 87 & 0.74 \\
\hline 4 & M & 22.9 & 31 & Dp Df cockroach & 14.3 & 118 & NA & 71 & 27.1 & 88 & 1.83 \\
\hline 6 & $\mathrm{~F}$ & 15.2 & 36 & Dp Df cockroach & 15.3 & 76.1 & ICS/LABA & 24 & 10.0 & 82 & 0.81 \\
\hline 7 & $\mathrm{~F}$ & 20.3 & 31 & Dp Df cat cockroach & 51.6 & 451 & SABA & 82 & 26.6 & 83 & 0.71 \\
\hline 8 & $\mathrm{~F}$ & 15.4 & 19 & Dp Df cockroach & 50.6 & 205 & ICS/LABA & 31 & 29.0 & 108 & 15.59 \\
\hline 9 & M & 27.0 & 55 & Dp Df dog cat & 100 & 771 & ICS/LABA & 72 & 28.3 & 80 & 0.84 \\
\hline 12 & $\mathrm{~F}$ & 27.5 & 31 & Dp Df dog & 13.4 & 103 & SABA & 147 & 47.7 & 89 & 0.57 \\
\hline 13 & $\mathrm{~F}$ & 18.5 & 50 & Dp Df & 61 & 209 & SABA & 20 & 4.1 & 114 & 10.32 \\
\hline 14 & $\mathrm{~F}$ & 22.8 & 29 & Dp Df dog & 83.8 & 368 & ICS/LABA & 73 & 48.6 & 83 & 6.30 \\
\hline 15 & M & 23.5 & 26 & Dp Df dog & 38 & 236 & ICS & 125 & 2.6 & 92 & 5.81 \\
\hline 16 & M & 24.3 & 29 & Dp Df cockroach & 66.9 & 382 & ICS/LABA & 25 & 8.0 & 85 & 8.56 \\
\hline 17 & $\mathrm{~F}$ & 22.0 & 26 & Dp Df dog cockroach & 35.1 & 239 & ICS/LABA & 34 & 6.4 & 79 & 0.05 \\
\hline 18 & $\mathrm{~F}$ & 23.2 & 41 & Dp Df dog cockroach & 38.9 & 645 & ICS/LABA & 65 & 47.8 & 85 & 6.06 \\
\hline
\end{tabular}

*, medication used as need for the control of asthma before the enrollment of this study. F, female; M, male; Dp, Dermatophagoides pteronyssinus; Df, Dermatophagoides farina; SABA, short-acting Beta2 agonist; ICS, inhaled corticosteroid; ICS/LABA, inhaled corticosteroid combined with long-acting Beta2 agonist; FeNo, fractional exhaled nitric oxide; T-IgE, total IgE; Eos, eosinophils; Sp, sputum.

were cough, chest tightness, dry throat, and all symptoms could be released after rest or inhaling Salbutamol. No serious systemic adverse effect was reported. The mean $\mathrm{FEV}_{1} \%$ pred and $\mathrm{PC}_{20} \mathrm{FEV}_{1}$ to Methacholine $\left(\mathrm{PC}_{20^{-}}\right.$ Mch) before and 24 hours post allergen challenge were $87.8 \% \pm 10.6 \%$ and $81.0 \% \pm 10.8 \%, 1.58$ (4.39) and 0.81 (2.38) $\mathrm{mg} / \mathrm{mL}$, both $\mathrm{P}<0.05$.

\section{Eosinophils in sputum, nasal lavage, and PB before and after allergen challenge}

The percentages of eosinophils in sputum and nasal lavage were $20.70 \% \pm 16.76 \%$ and $39.36 \% \pm 23.30 \%$ respectively before allergen challenge. At 7 hours post allergen challenge, the percentages of eosinophils increased in sputum $(40.45 \% \pm 25.47 \%, \mathrm{P}=0.000)$ while there was an increase with no statistical difference found in nasal lavage $(48.07 \% \pm 32.01 \%$,
$\mathrm{P}=0.167)$. Compared with that before allergen challenge, at 24 hours post allergen challenge, the eosinophils were still increased in sputum $(27.86 \% \pm 17.34 \%, \mathrm{P}=0.026)$ while no significant difference was found in nasal lavage (38.58\% $\pm 25.36 \%, \mathrm{P}=0.894)$. The percentage of eosinophils in $\mathrm{PB}$ was increased from baseline $4.82 \% \pm 1.80 \%$ to $6.91 \% \pm 2.68 \%(\mathrm{P}=0.000)$ with no change found in neutrophils $(58.07 \% \pm 12.46 \%$ and $60.93 \% \pm 9.14 \%, \mathrm{P}=0.389$; Table 3$)$.

\section{FeNO values before and after allergen bronchial challenge}

The values of FeNO were 55 [54] ppb, 50 [32] ppb, and 69 [56] ppb before, at 7 and 24 hours after allergen challenge respectively, significantly increased only at 24 hours after allergen challenge $(\mathrm{P}<0.05)$, show in Figure 3. There was a significant correlation between the BMI and FeNO in baseline $(\mathrm{r}=0.55, \mathrm{P}=0.017)$. 
Table 2 Results of allergen bronchial challenge

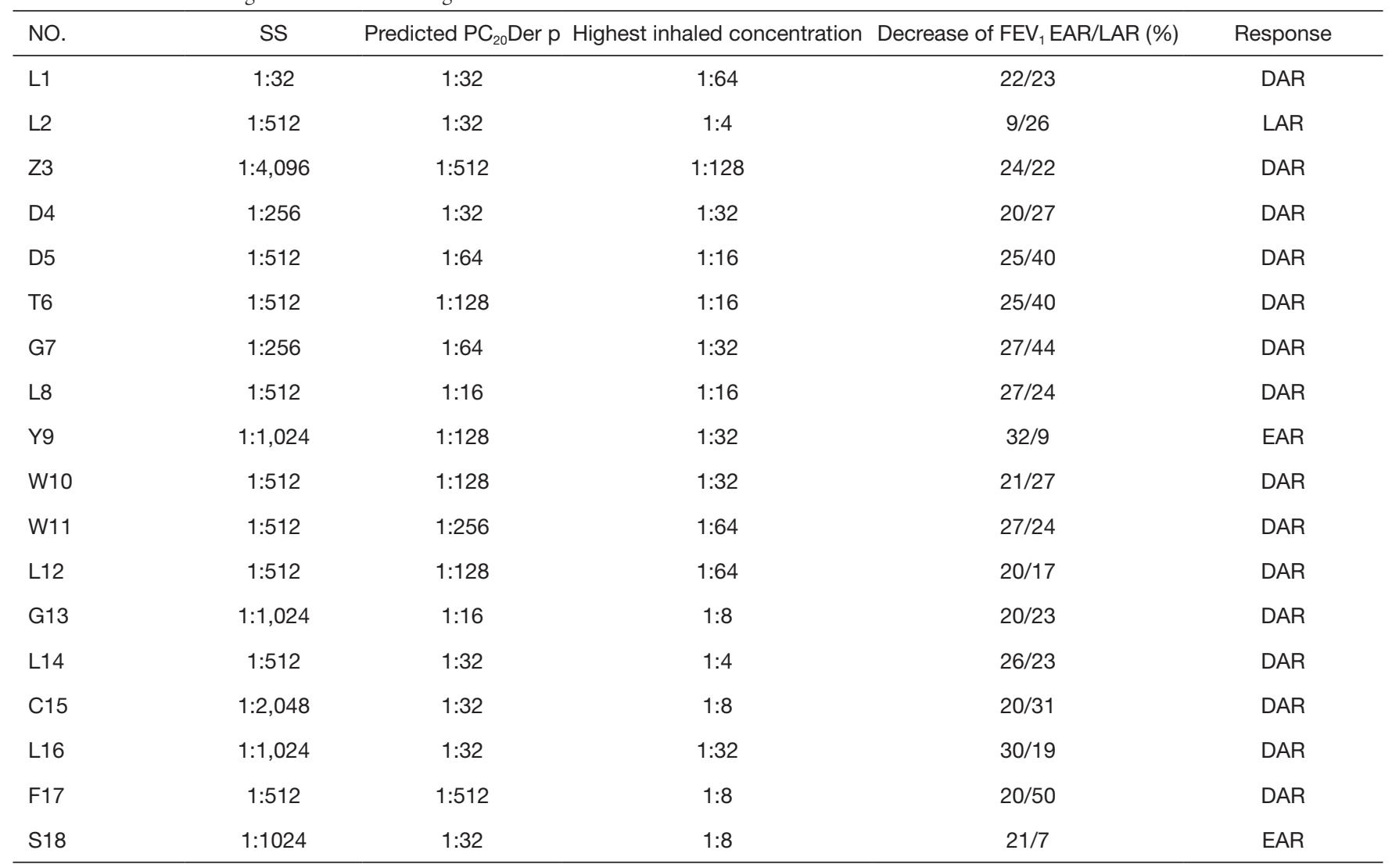

SS, skin test end-point titration; EAR, early asthmatic response; LAR, late asthmatic response; DAR, dual asthmatic response.

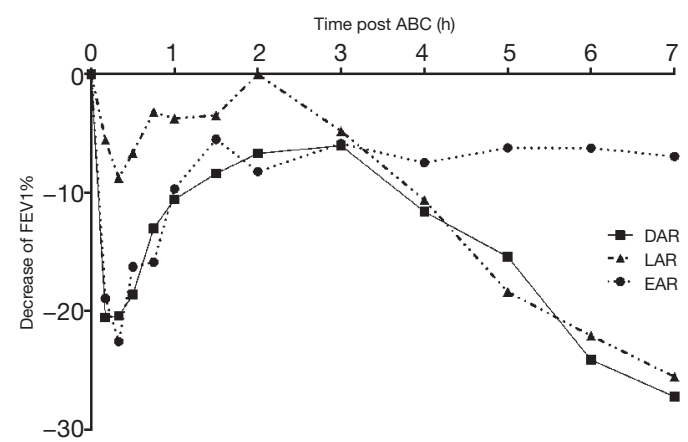

Figure 2 Decrease of $\mathrm{FEV}_{1}$ (\%) during the $\mathrm{ABC}$ test (DAR $\mathrm{n}=15$, EAR $n=2$, LAR $n=1)$. ABC, allergen bronchial challenge; DAR, dual asthmatic response; EAR, early asthmatic response; LAR, late asthmatic response.

\section{Correlations between AHR, allergen sensitization, and eosinophils}

The decrease of $\mathrm{FEV}_{1} \%$ during EAR was positively correlated with Der p s-IgE and total $\operatorname{IgE}(\mathrm{t}-\mathrm{IgE})(\mathrm{r}=0.515$, $\mathrm{P}=0.029$ and $\mathrm{r}=0.542, \mathrm{P}=0.020$ ), negatively correlated with $\mathrm{PC}_{20}$ Der $\mathrm{p}(\mathrm{r}=-0.716, \mathrm{P}=0.001)$, while the decrease of $\mathrm{FEV}_{1} \%$ during LAR was correlated with the percentage of eosinophils in sputum $(\mathrm{r}=0.507, \mathrm{P}=0.032) ; \mathrm{PC}_{20}$ Der $\mathrm{p}$ was correlated with $\mathrm{t}-\mathrm{IgE} / \mathrm{s}-\mathrm{IgE}$ ratio $(\mathrm{r}=0.456, \mathrm{P}=0.046)$, correlated with $\log \left(\mathrm{PC}_{20} \mathrm{Mch}\right)(\mathrm{r}=0.497, \mathrm{P}=0.036)$ post allergen bronchial challenge, and negatively correlated with the percentage of eosinophils in blood at 24 hours post allergen bronchial challenge $(\mathrm{r}=-0.533, \mathrm{P}=0.028)$. Eosinophils in sputum were positively correlated with 
Table 3 Changes of airway inflammation before and after allergen challenge

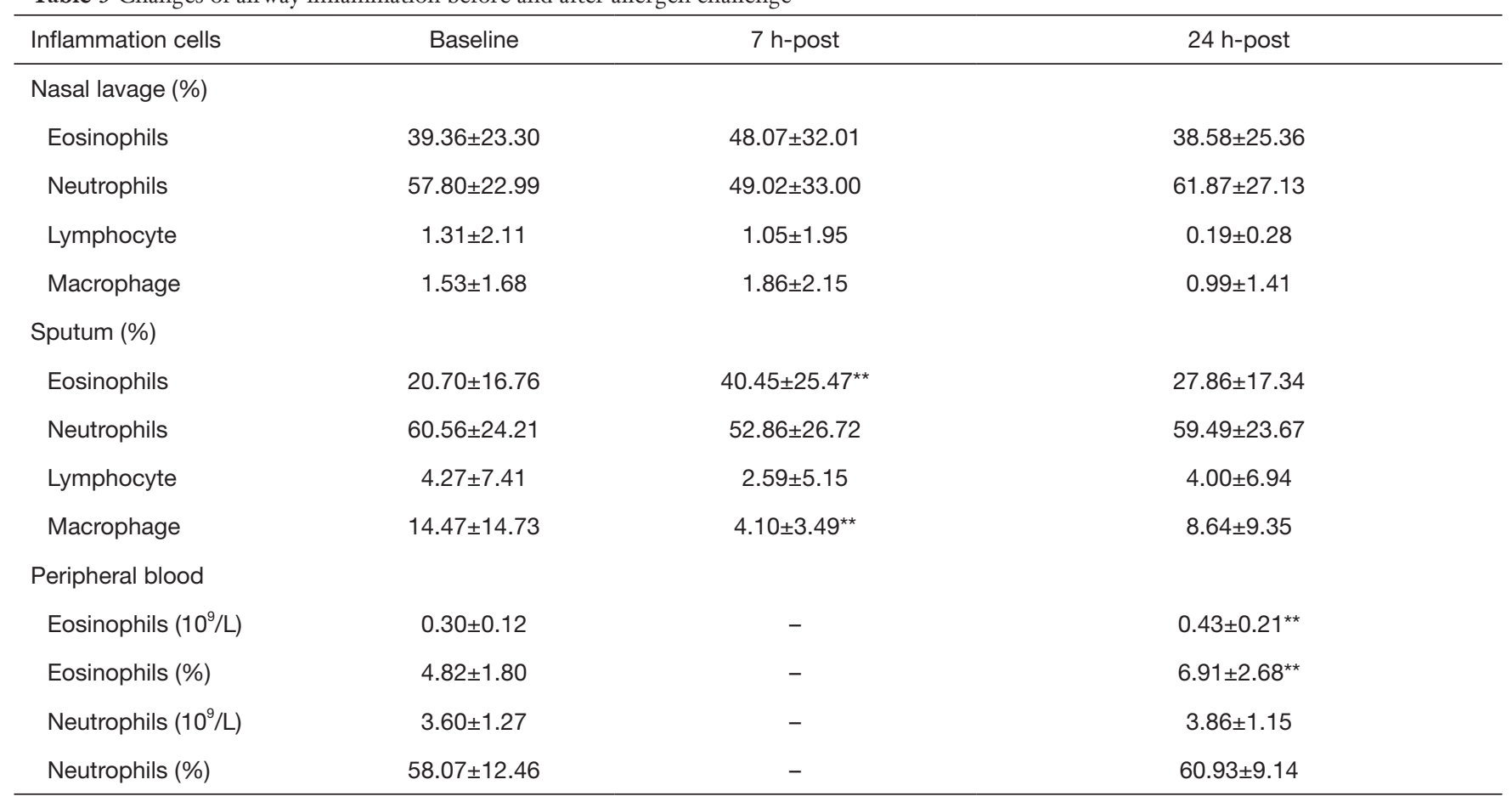

${ }^{* *}, \mathrm{P}<0.01$, compared with baseline.

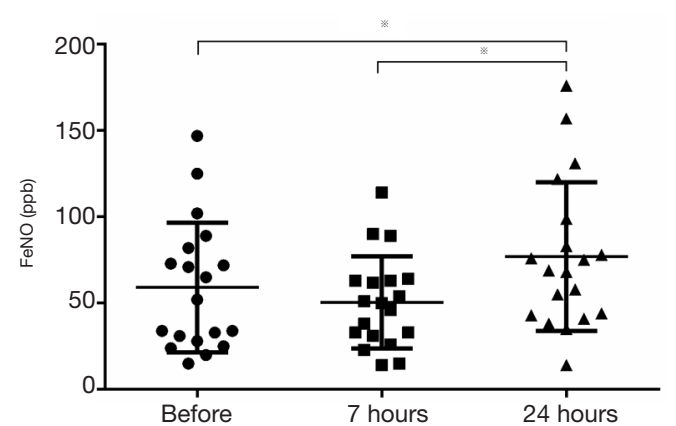

Figure 3 Values of FeNO before and after allergen bronchial challenge. ${ }^{*}, \mathrm{P}<0.05$. Distribution of FeNO, the values of $\mathrm{FeNO}$ decreased without significant at 7 hours and significantly increased at 24 hours after allergen bronchial challenge. FeNo, fractional exhaled nitric oxide.

eosinophils in $\mathrm{PB}$ before and after allergen challenge, respectively (both $\mathrm{P}<0.05$ ).

\section{Discussion}

To our knowledge, this is the first study to investigate the upper and lower airway responses to HDM allergen bronchial challenge in allergic asthma patients in China. In this study, we aimed to establish the standardized methodology and evaluate the safety of allergen bronchial challenge in allergic asthma patients, and explored the effects of HDM allergen bronchial challenge on eosinophils in the secretion of upper and lower airways and PB. The correlations between airway inflammation and AHR and clinical aspects were also analyzed.

We have found that all asthma with AR patients were sensitive to HDM allergen bronchial challenge, and the majority $(83 \%)$ of them had DAR. The average decrease rate of $F E V_{1}$ during $L A R$ phase was larger than the values during EAR phase and the reason may be related to the heavy lower airway eosinophilic inflammation of the subjects in this study. The prevalence of LAR in asthma patients ranged from $10 \%$ to $70 \%$ in different reports, with higher prevalence in children than adults $(8,13)$. It has been reported that different allergens inhaled for challenge resulted in diversity proportion of LAR, and in a retrospective study, the prevalence of LAR was $70 \%$ (203/290) in total, $75 \%(85 / 113)$ challenged with HDM, $68 \%(79 / 116)$ challenged with animal allergen, and $64 \%$ (39/61) challenged with pollen (13). HDM allergen 
(perennial allergen) inhalation bronchial challenge induced higher prevalence rate of LAR than pollen (seasonal allergens) and animal fur allergens (Cat) (13). In our study, HDM was the only allergen inhaled, which might explain the higher proportion of LAR than previous reports $(8,13)$.

The mechanism and predictor of LAR to allergen bronchial challenge have not been fully understood. It has been reported that the level of allergen specific $\mathrm{IgE}$ in serum can predict the occurrence of $\operatorname{LAR}(10,23,24)$. In our study, all patients were sensitive to HDM with high level of Der p s-IgE $(43.2 \pm 25.9 \mathrm{kU} / \mathrm{L})$ in serum, and HDM allergen was the only allergen used for the bronchial provocation test. This may explain a relatively higher prevalence of LAR in our study compared to that in the previous studies with multiple allergens for challenge. However, there was not baseline serum $s-\operatorname{IgE}$ data in previous studies for comparison $(8,13)$. In addition to the type of inhaled allergen, baseline airway responsiveness to methacholine could also be a determinant of late responses (13). In our study, the mean value of $\mathrm{PC}_{20}-\mathrm{Mch}$ in baseline for subjects with LAR was $1.30(0.05-15.59) \mathrm{mg} / \mathrm{mL}$, and $\mathrm{PC}_{20}-\mathrm{Mch}$ was well correlated with $\mathrm{PC}_{20} \mathrm{Der} \mathrm{p}$. Boulet et al. found that dual responders with LAR had significantly lower prechallenge $\mathrm{PC}_{20}$ to histamine or methacholine $(10,13)$. In our study, the decreased $\mathrm{PC}_{20}-\mathrm{Mch}$ after allergen bronchial challenge might be caused by the increased eosinophils in lower airways, as airway inflammation influence or determine AHR (25).

Chronic airway inflammation is one of the major features of $\mathrm{AR}$ and asthma. In this study, the percentage of eosinophils in $\mathrm{PB}$ and sputum were significantly increased after allergen bronchial challenge. Although airway responsiveness was different with various kind of allergen inhaled, airway inflammatory subtype in sputum is unlikely to be influenced by the type of inhaled allergen $(13,25,26)$. The increased eosinophils in airways might be derived from bone marrow and $\mathrm{PB}$ after allergen challenge (9,27-29), and airway inflammation changed over time, the eosinophilic inflammation may reach the peak level at different time points in different organs after allergen exposure. It has reported that segmental allergen bronchial provocation induced nasal inflammation at 24 hours after challenge in AR patients (27). Although having impact on each other, the interaction of inflammation between upper and lower airways is not very clear, which may be not only derived from or associated with systemic inflammation, and local allergic reaction may also play important roles. In a previous study from our institute, it has been reported that an isolated lower airway allergen challenge had not obvious impact on nose allergic inflammation in mice, suggesting that the 'bidirectional' relationship between nasal and bronchial inflammation is asymmetric (30). Relationship between the systemic and local inflammation in AR with asthma patients need further investigation.

FeNO is a good indicator of lower airway eosinophilic inflammation and well correlated with the percentages of eosinophils in sputum, so it was often used for the diagnosis and management of asthma or evaluation of lower airway inflammation (31). In our study, most of the patients had higher $\mathrm{FeNO}$ value than the upper normal limit value (25 ppb). FeNO decreased a little at 7 hours and then significantly increased at 24 hours after allergen bronchial challenge, while the percentages of eosinophils significantly increased at both 7 hours and 24 hours after allergen bronchial challenge. The reason for the decrease of FeNO at 7 hours after challenge may be the contraction of the lower airways during LAR, as most subjects $(15 / 18)$ in this study had LAR ( $\mathrm{FEV}_{1}$ decreased during 3 to 7 hours after allergen challenge), which might interfere the diffusion and breath out of the nitric oxide. At 24 hours after allergen bronchial challenge, the contracted lower airways released and $\mathrm{FEV}_{1}$ recovered to the pre-challenge levels, with the increased eosinophilic inflammation in lower airway, the level of FeNO increased, which is consistent to the results of previous study (32). In the further study, we plan to measure the FeNO after a dilation test immediately after allergen challenge and during LAR to distinguish the effects between bronchoconstriction and airway inflammation.

Allergen exposure induced type 2 inflammation dominated by eosinophils increased in systemic (bone marrow or $\mathrm{PB}$ ) or infiltration in organs. In this study, eosinophils in $\mathrm{PB}$ and the production of upper and lower airway were increased after HDM allergen inhalation. Eosinophils in sputum well correlated with eosinophils in PB. Eosinophils presence at one site of the airways, may release into the bloodstream several cytokines that can lead to the stimulation of the bone marrow, which may function as a systemic amplifier of such an eosinophilic inflammation in both sites of airway $(4,32)$. Allergen specific $\operatorname{IgE}$ level may correlate with or influence the severity of inflammation and AHR. Airway eosinophilic inflammation play a vital role in the mechanism of AHR with a close correlation. In this study, both the levels of HDM s-IgE and total $\operatorname{IgE}$ were correlated with the response of $\mathrm{FEV}_{1}$ in $\mathrm{EAR}$, and the percentage of eosinophils in sputum was well correlated with the response of $\mathrm{FEV}_{1}$ in LAR, which support the fact 
that $\operatorname{IgE}$ is the key factor and mediated allergic reaction (eosinophilic inflammation and AHR).

There are some limitations of this study. Firstly, PB inflammatory cells count was performed before and at 24 hours after allergen challenge, without knowing the changes during the LAR (7 hours after challenge), as well as its association with airway local inflammation. Secondly, the sample size was insufficient for subgroup analysis of the changes of airway inflammation between subjects with EAR/LAR only (few subjects with EAR or LAR only in this study) and those with DAR. Meanwhile, there was not a normal control group due to ethical consideration. Thirdly, the diluents bronchial challenge was not performed. We could not identify those patients who might be positive to diluents, although the diluent was inhaled as the control during Mch bronchial provocation test in this study. Lastly, in terms of potential carry-over effect (data validity), most of the allergen challenge study follow a washout period for ICS of at least 4 weeks. However, the washout period for ICS was defined as 2 weeks in this study. Actually, almost all of the subjects stopped the use of ICS for more than 4 weeks, as subjects use SABA, ICS or ICS/LABA as needed, not for maintenance.

\section{Conclusions}

In conclusion, following standard operation procedure, HDM allergen bronchial challenge is safe, which can elicit lower airway and systemic allergic response, but does not induce significant increase of eosinophils in nasal lavage in Chinese asthmatic patients with AR.

\section{Acknowledgments}

Thanks prof. Mark Inman for his review and helpful advice on this manuscript.

Funding: This project was supported by National Key R\&D Program 2018YFC1311900; Guangdong Basic and Applied Fundamental Research Fund (2020A1515110007); Zhongnanshan Medical Foundation of Guangdong Province (ZNSA-2020003, No. 202102010347 ; ZNSA2020013). Open Project Grant (2014SKLRD- O11) from the State Key Lab of Respiratory Disease, Guangzhou Medical University.

\section{Footnote}

Reporting Checklist: The authors have completed the STROBE Checklist. Available at https://dx.doi. org/10.21037/jtd-20-2876

Data Sharing Statement: Available at https://dx.doi. org/10.21037/jtd-20-2876

Conflicts of Interest: All authors have completed the ICMJE uniform disclosure form (available at https://dx.doi. org/10.21037/jtd-20-2876). NZ serves as unpaid Editorin-Chief of Journal of Thoracic Disease. The authors have no other conflicts of interest to declare.

Ethical Statement: The authors are accountable for all aspects of the work in ensuring that questions related to the accuracy or integrity of any part of the work are appropriately investigated and resolved. The study was conducted in accordance with the Declaration of Helsinki (as revised in 2013). The study protocol was approved by the Ethics Committee of the First Affiliated Hospital of Guangzhou Medical University (NCT02504528), and written informed consent was obtained and signed by each subject prior to the study.

Open Access Statement: This is an Open Access article distributed in accordance with the Creative Commons Attribution-NonCommercial-NoDerivs 4.0 International License (CC BY-NC-ND 4.0), which permits the noncommercial replication and distribution of the article with the strict proviso that no changes or edits are made and the original work is properly cited (including links to both the formal publication through the relevant DOI and the license). See: https://creativecommons.org/licenses/by-nc-nd/4.0/.

\section{References}

1. Huang K, Yang T, Xu J, et al. Prevalence, risk factors, and management of asthma in China: a national cross-sectional study. Lancet 2019;394:407-18.

2. Fu QL, Du Y, Xu G, et al. Prevalence and Occupational and Environmental Risk Factors of Self-Reported Asthma: Evidence from a Cross-Sectional Survey in Seven Chinese Cities. Int J Environ Res Public Health 2016. doi: 10.3390/ ijerph13111084.

3. Togias A, Gergen PJ, Hu JW, et al. Rhinitis in children and adolescents with asthma: Ubiquitous, difficult to control, and associated with asthma outcomes. J Allergy Clin Immunol 2019;143:1003-1011.e10.

4. Poddighe D, Brambilla I, Licari A, et al. Pediatric 
rhinosinusitis and asthma. Respir Med 2018;141:94-9.

5. Wang W, Xian M, Xie Y, et al. Aggravation of airway inflammation and hyper-responsiveness following nasal challenge with Dermatophagoides pteronyssinus in perennial allergic rhinitis without symptoms of asthma. Allergy 2016;71:378-86.

6. Diamant Z, Gauvreau GM, Cockcroft DW, et al. Inhaled allergen bronchoprovocation tests. J Allergy Clin Immunol 2013;132:1045-1055.e6.

7. Gauvreau GM, El-Gammal AI, O'Byrne PM. Allergeninduced airway responses. Eur Respir J 2015;46:819-31.

8. Robertson DG, Kerigan AT, Hargreave FE, et al. Late asthmatic responses induced by ragweed pollen allergen. J Allergy Clin Immunol 1974;54:244-54.

9. Li J, Huang Y, Lin X, et al. Influence of degree of specific allergic sensitivity on severity of rhinitis and asthma in Chinese allergic patients. Respir Res 2011;12:95.

10. Poddighe D, Mathias CB, Brambilla I, et al. Importance of basophils in eosinophilic asthma: the murine counterpart. J Biol Regul Homeost Agents 2018;32:335-9.

11. Gauvreau GM, Watson RM, O'Byrne PM. Kinetics of allergen-induced airway eosinophilic cytokine production and airway inflammation. Am J Respir Crit Care Med 1999;160:640-7.

12. Dorman SC, Sehmi R, Gauvreau GM, et al. Kinetics of bone marrow eosinophilopoiesis and associated cytokines after allergen inhalation. Am J Respir Crit Care Med 2004;169:565-72.

13. Boulet LP, Gauvreau G, Boulay ME, et al. Allergeninduced early and late asthmatic responses to inhaled seasonal and perennial allergens. Clin Exp Allergy 2015;45:1647-53.

14. Li J, Sun B, Huang Y, et al. A multicentre study assessing the prevalence of sensitizations in patients with asthma and/or rhinitis in China. Allergy 2009;64:1083-92.

15. The Global Strategy for Asthma Management and Prevention. Global Initiative for Asthma (GINA) 2017. Available online: http://www.ginasthma.org

16. Brożek JL, Bousquet J, Agache I, et al. Allergic Rhinitis and its Impact on Asthma (ARIA) guidelines-2016 revision. J Allergy Clin Immunol 2017;140:950-8.

17. Wang H, Lin X, Hao C, et al. A double-blind, placebocontrolled study of house dust mite immunotherapy in Chinese asthmatic patients. Allergy 2006;61:191-7.

18. Cockcroft DW, Killian DN, Mellon JJ, et al. Bronchial reactivity to inhaled histamine: a method and clinical survey. Clin Allergy 1977;7:235-43.

19. Zhu Z, Xie Y, Guan W, et al. Effects of leukotriene
D4 nasal challenge on bronchial responsiveness and inflammation in asthmatic patients with allergic rhinitis. J Thorac Dis 2017;9:271-7.

20. Luo W, Chen Q, Chen R, et al. Reference value of induced sputum cell counts and its relationship with age in healthy adults in Guangzhou, Southern China. Clin Respir J 2018;12:1160-5.

21. Frøssing L, Hartvig Lindkaer Jensen T, Østrup Nielsen $\mathrm{J}$, et al. Automated cell differential count in sputum is feasible and comparable to manual cell count in identifying eosinophilia. J Asthma 2021. [Epub ahead of print]. doi: 10.1080/02770903.2020.1868498.

22. American Thoracic Society; European Respiratory Society. ATS/ERS recommendations for standardized procedures for the online and offline measurement of exhaled lower respiratory nitric oxide and nasal nitric oxide, 2005. Am J Respir Crit Care Med 2005;171:912-30.

23. Barnig C, Purohit A, Casset A, et al. Nonallergic airway hyperresponsiveness and allergen-specific $\operatorname{IgE}$ levels are the main determinants of the early and late asthmatic response to allergen. J Investig Allergol Clin Immunol 2013;23:267-74.

24. Amaral AFS, Newson RB, Abramson MJ, et al. Changes in $\mathrm{IgE}$ sensitization and total $\mathrm{IgE}$ levels over 20 years of follow-up. J Allergy Clin Immunol 2016;137:1788-1795.e9.

25. Revez JA, Killian KJ, O'Byrne PM, et al. Sputum cytology during late-phase responses to inhalation challenge with different allergens. Allergy 2018;73:1470-8.

26. Oddera S, Silvestri M, Penna R, et al. Airway eosinophilic inflammation and bronchial hyperresponsiveness after allergen inhalation challenge in asthma. Lung 1998;176:237-47.

27. Braunstahl GJ, Kleinjan A, Overbeek SE, et al. Segmental bronchial provocation induces nasal inflammation in allergic rhinitis patients. Am J Respir Crit Care Med 2000;161:2051-7.

28. Asosingh K, Hanson JD, Cheng G, et al. Allergen-induced, eotaxin-rich, proangiogenic bone marrow progenitors: a blood-borne cellular envoy for lung eosinophilia. J Allergy Clin Immunol 2010;125:918-25.

29. El-Gammal A, Oliveria JP, Howie K, et al. Allergeninduced Changes in Bone Marrow and Airway Dendritic Cells in Subjects with Asthma. Am J Respir Crit Care Med 2016;194:169-77.

30. Xie J, Xi Y, Zhang Q, et al. An intratracheal challenge murine model of asthma: can bronchial inflammation affect the nose? Allergy Asthma Immunol Res 2015;7:76-82.

31. Haccuria A, Michils A, Michiels S, et al. Exhaled nitric 
oxide: a biomarker integrating both lung function and airway inflammation changes. J Allergy Clin Immunol 2014;134:554-9.

32. Malaviya R, Zhou Z, Raymond H, et al. Repeated

Cite this article as: Zhu Z, Wang H, Xie Y, An J, Hu Q, Xia S, Li J, O'Byrne P, Zheng J, Zhong N. Response of upper and lower airway inflammation to bronchial challenge with house dust mite in Chinese asthmatics: a pilot study. J Thorac Dis 2021;13(8):4988-4998. doi: 10.21037/jtd-20-2876 exposure of house dust mite induces progressive airway inflammation in mice: Differential roles of CCL17 and IL13. Pharmacol Res Perspect 2021;9:e00770. 